\title{
Navigating the Job Search as a Low-Resourced Job Seeker
}

\author{
Earnest Wheeler \\ University of Michigan \\ Ann Arbor, MI, USA \\ earnestw@umich.edu
}

\author{
Tawanna R. Dillahunt \\ University of Michigan \\ Ann Arbor, MI, USA \\ tdillahu@umich.edu
}

\begin{abstract}
The Internet is providing increasing access to information about employment opportunities, but not everyone can leverage it effectively. Research suggests that job seekers with limited access to Internet technologies are being left behind, while those with limited social resources are expected to rely on the Internet even more. In this work, we conducted indepth semi-structured interviews with 11 low-resourced job seekers in a metropolitan area in the Midwestern United States to understand how social and digital resources support their efforts to find work. We find that online resources support job seekers in finding relevant jobs via search, but do not help them identify opportunities to improve their job search process or increase their chances of securing employment. We recommend that systems aiming to support low-resourced job seekers design for deeper engagement with their users across the job search process, to help users recognize ways to improve on their existing practices.
\end{abstract}

\section{ACM Classification Keywords}

H.5.m. Information Interfaces and Presentation (e.g. HCI): Miscellaneous

\section{Author Keywords}

underserved job seekers; information seeking; employment; design; digital divide.

\section{INTRODUCTION}

The majority of Americans who are looking for jobs use online resources [24]. As the Internet becomes more prominent in how individuals look for work, it has become an increasingly common way for employers to look for workers, reducing opportunities to encounter recruiters or succeed offline [15]. While this shift reduces the cost of searching for work, it also raises barriers for those with low digital literacy, limited access to Internet-enabled devices, and low educational attainment $[5,24,29]$. To achieve similar outcomes to job seekers with high digital literacy, those with lower efficacy with Internet search must turn to other forms of support [28].

\footnotetext{
Permission to make digital or hard copies of all or part of this work for personal or classroom use is granted without fee provided that copies are not made or distributed for profit or commercial advantage and that copies bear this notice and the full citation on the first page. Copyrights for components of this work owned by others than the author(s) must be honored. Abstracting with credit is permitted. To copy otherwise, or republish, to post on servers or to redistribute to lists, requires prior specific permission and/or a fee. Request permissions from permissions@acm.org.

CHI 2018, April 21-26, 2018, Montreal, QC, Canada

(c) 2018 Copyright held by the owner/author(s). Publication rights licensed to ACM ISBN 978-1-4503-5620-6/18/04 ..\$15.00
}

DOI: https: //doi .org/10.1145/3173574. 3173622
A lack of social connections has historically been another major barrier to getting a job $[13,25]$. Recent work in a community facing economic decline found that individuals felt that they lacked connections to others with high expertise or important resources, and lacked opportunities to establish those connections [4]. Individuals in the study also reported significant distrust within their communities, and they perceived institutional resources as apathetic towards their circumstances [4]. Past research shows that weak bridging ties-distant personal contacts that connect distinct social groups-are vital for community well-being [23], and particularly important when searching for novel information and job opportunities [12, 25].

More recent work on the job seeking behaviors of US college students suggests that students from minority ethnic groups, who may have fewer institutional ties to career opportunities, take advantage of Internet resources in order to achieve their goals [22]. Like those with technical barriers who turn to their social networks for success, those with limited social resources and high digital literacy can turn to the Internet; however, when technical and social issues intersect, the path to success is far less clear. Intuitively, this is the purpose of employment agencies and other public institutions, but previous work argues that many low-resourced job seekers struggle to derive benefits from these sources [25].

In this study, we seek to understand how the job search process has changed for low-resourced individuals due to online employment tools and other digital platforms. We examine the role of external sources of information and support in the job search process of low-resourced job seekers, extending prior work on job seeking and shedding light on the expanding role of technology in the experiences of disadvantaged job seekers. We conducted semi-structured interviews with 11 low-resourced job seekers in a metropolitan area in the Midwestern United States (US), about their recent job searches, their sources of information and support, and the challenges they perceive in the job search process. Specifically, we address the following questions:

- What are the most important sources of information for low-resourced job seekers?

- How do online resources improve, impair, and change the job search process for low-resourced job seekers?

Our findings confirm past research that offline connections, access to computers, and digital literacy skills play a major role in their job search process. Our findings also suggest that the transition of job applications from offline to online increases 
the importance of offline job referrals and connections to insiders. At the same time, online social media provides new avenues for job seekers to leverage their social connections and access insider information about companies. Ultimately, we find that our participants valued online resources for obtaining factual information (such as available jobs, pay rates, and benefits), but they considered any information from social connections more trustworthy. They preferred social connections as sources of advice, opinions, or information throughout the job search process.

In this study, we investigate the role of ICTs in the job search process of job seekers with limited resources, from an area suffering from widespread poverty. We contribute a qualitative study of the job-related information practices of low-resourced job seekers, and their perspectives on job-seeking in the Internet age. We extend prior literature by exploring the role of Information Communication Technologies (ICTs) in the job search process. We contribute a decomposition of the job search process into four stages: learning about available jobs, accessing important job details, applying to jobs, and securing a job offer. We use these stages of job search to clarify how ICTs affect the job search process of low-resourced job seekers, and to suggest design recommendations for online employment platforms to engage with job seekers throughout their job search and career development process.

\section{RELATED WORK}

Our study builds on research from sociology as well as more recent research in HCI. This section outlines the historical research on problems of employment among low-socioeconomic status (SES) populations in the US, and then describes the line of inquiry within HCI that our study extends.

\section{Looking for Work}

Prior work has consistently demonstrated the importance of personal social connections for job-seeking, and informationseeking in general. Granovetter's work asserted the importance of acquaintances for many dimensions of life, and particularly in the job search $[12,13]$. However, his work emphasized that these connections were more beneficial for those with high SES, and that the lack of these connections were a major issue for lower SES populations [14]. Chatman's ethnographic studies of various marginalized populations further investigated this issue, defining a condition of "information poverty," where perceived norms and social isolation cause affected individuals to believe they have no ways to acquire important information [2,3]. More recently, Smith's work argues that a combination of sparse social networks and lack of trust are the primary cause of persistent unemployment among lowincome African-Americans [25]. Overall, the past research indicates that populations who begin with limited social and economic resources face an uphill battle in finding sustainable employment, one that they largely face alone.

These findings paint a setting in which the Internet could have enormous impact; in the general context of job seekers, it certainly has. According to a 2015 Pew Report, $79 \%$ of recent job seekers relied on online resources or information in their most recent job search, and 34\% said that the Internet was the most important resource in their search [24], including looking for or researching jobs, letting friends know about jobs, and finding jobs to apply for. However, Pew also reported that the popularity of online resources was inversely related with the education level of respondents, and those with less than a college education were significantly less confident in performing many job-related tasks online [24]. We contribute to this literature by investigating, in detail, the role of technology in the job seeking practices of underserved individuals.

\section{$\mathrm{HCl}$ and Low-Resourced Workers}

Recently, there has been an uptick in HCI research that focuses on improving the economic conditions of low-resourced workers in the US. Dombrowski et al. identify key sociotechnical practices that low-wage workers engage in to combat wage theft, and contribute design recommendations to support their efforts [9]. Dillahunt et al.'s work has investigated the potential of ICTs to promote socially beneficial behaviors $[4,5,6$, 7]. In line with past work [3], she finds major issues of distrust, both between community members and towards external resources [4]. Work by Woelfer and Hendry finds that homeless young people experience similar distrust and pessimism in the job search process, and struggle to present themselves well in online contexts [30,31]. More recent work on the subject by Hendry et al. investigates possible community interventions to address joblessness among homeless youth [18]. Further studies explored the role that sharing economy applications (e.g., Lyft, TaskRabbit, NeighborGoods) could play in building social capital in these communities [6,7] and the unique barriers of designing for low-resourced populations [5]. Despite these threads of research, the role of ICTs in the job search process remains underexplored for many low-resourced populations. In this work, we expand the HCI community's understanding of the perspectives and challenges of low-resourced job seekers in the job search and the role that Internet technologies play in that process.

\section{METHOD}

\section{Participants}

We recruited participants in the area surrounding Detroit, Michigan, which has an estimated $25 \%$ poverty rate and a median household of $\$ 42,043$ [1]. We reached out to participants through flyers and advertisements distributed to community partners; local businesses such as barbershops, hair salons, and restaurants; bus stations; and on Craigslist. We took this approach to reach job seekers with limited digital access, small social networks, and those who relied heavily on public institutions. We define our participants as low-resourced job seekers based on the following criteria: (1) they self-report searching for a job in the last six months, (2) they live in an area with a high rate of poverty, (3) they lack a four-year college degree, which previous research shows to be strongly correlated with computing efficacy [24, 29] and social capital [17, 20], and (4) they describe themselves as Black/African-American, a historically underserved and marginalized population [25].

Table 1 provides basic demographic information about our participants. The average age of our participants was 48 years old (Median=47, SD=12) and in terms of education attainment, two $(\mathrm{N}=2)$ participants had an Associate's degree; the 


\begin{tabular}{lrrrr} 
& & \multicolumn{2}{c}{ Participant Demographics } & \\
\cline { 3 - 4 } Name & Gender & Race/Ethnicity & Age & 2016 Income \\
\hline Aaron & M & Black/AA & 53 & less than $\$ 15 \mathrm{k}$ \\
Marika & $\mathrm{F}$ & Black/AA & N/A* & \$15k to \$25k \\
Talia & $\mathrm{F}$ & Black/AA & 31 & N/A* \\
Tanzer & $\mathrm{M}$ & Black/AA & 60 & \$15k to \$25k \\
Annie & $\mathrm{F}$ & Black/AA & 47 & less than $\$ 15 \mathrm{k}$ \\
Charlie & $\mathrm{M}$ & Black/AA & 32 & \$25k to $\$ 35 \mathrm{k}$ \\
Brandon & $\mathrm{M}$ & Black/AA & 60 & $\$ 25 \mathrm{k}$ to $\$ 35 \mathrm{k}$ \\
Luke & $\mathrm{M}$ & Black/AA & 44 & less than $\$ 15 \mathrm{k}$ \\
Teresa & $\mathrm{F}$ & Black/AA & 69 & less than $\$ 15 \mathrm{k}$ \\
Helen & $\mathrm{F}$ & Black/AA & 45 & less than $\$ 15 \mathrm{k}$ \\
Winona & $\mathrm{F}$ & Black/AA & 42 & less than $\$ 15 \mathrm{k}$
\end{tabular}

Table 1. Participant Demographics.

*: participant declined to share this information.

remaining nine $(\mathrm{N}=9)$ had a high school diploma or GED. The median reported income from 2016 was less than $\$ 15 \mathrm{k}$ ( $\mathrm{min}=$ $<\$ 15 \mathrm{k} ; \max =\$ 25 \mathrm{k}$ to $\$ 35 \mathrm{k})$. Five $(\mathrm{N}=5)$ participants were male, and six $(\mathrm{N}=6)$ were female.

\section{Data Collection}

We conducted 11 one-on-one semi-structured interviews to understand the experiences of low-resourced job seekers in an urban metropolitan area. On average, the interviews lasted 47 minutes $(\min =32 ; \max =57)$, and each subject was compensated with $\$ 15$ in cash. The interview protocol focused on the employment history of the participant, the challenges they faced in finding and maintaining employment, their experiences with online and offline employment resources, and how they sought information and assistance in the job search process. The interview concluded with a short questionnaire about demographics and technology use.

The research activities were conducted over three months. Detailed notes were taken during the sessions, and a memorandum was drafted by the first author within six hours of each interview. All interviews were recorded and transcribed except for one. The recording for one interview was corrupted, so we relied on the corresponding notes and memo for the analysis of that interview.

\section{Data Analysis}

We conducted four rounds of coding using grounded theory analysis [21] to identify themes around how people structured their job search and what resources they used. The first author reviewed the transcripts and memorandums and held discussions with the second author iteratively. Our initial themes were "getting more information about a job," "relying on wellconnected individuals," "social media and jobs," "maintaining important relationships" and "using the Internet to search for jobs." We used these themes to organize the data and refine the interview protocol. We used a grounded theory approach [21] to our analysis, which revealed the importance of structured goals or tasks in the information-seeking process of our participants. Later iterations of coding focused on translating these goals and tasks into a temporal framework of the stages of job search, grounded in the data.

\section{FINDINGS}

In this section, we present a four-stage framework of the job search process to convey the important themes of online and offline practices of our participants in the job search. In learning about available jobs, our participants gathered potential job openings or advertised their services as a worker. In $a c$ cessing important job details, they researched those potential openings to decide whether the job was right for them. In applying to jobs, they developed and submitted their applications and got advice on how to best present themselves in their resume and interviews. In securing a job offer, participants used their social connections to find referrals or insiders that provided support that improved their chances of getting a job. Within each stage, we highlight the ways that digital and social resources improve, impair, and alter the job search process of low-resourced job seekers.

Our study showed that the growing pervasiveness of the Internet empowers job seekers who possess high digital literacy, and provides access to valuable information for job seekers with limited social resources. However, the Internet does not eliminate the need for social resources, as many job seekers still rely on personal contacts to influence their hiring outcome, and our participants felt that information on the Internet is not as specific or trustworthy as what is found through offline contacts. Job seekers who turned to institutional resources (e.g., libraries, workforce development agencies, or community organizations) used them to access computer labs, resumé workshops, or job fairs.

\section{Learning about Available Jobs}

The most basic element of a job search is finding out about appropriate and available jobs. The majority of our participants found out about positions through personal contacts or "word of mouth" $(\mathrm{N}=10)$, which aligns with previous work [25]. Internet-based job tools enable job seekers to find out about many jobs, but social contacts connect job seekers with highly relevant and high-quality job opportunities. Of the eight $(\mathrm{N}=8)$ participants who used Facebook, seven $(\mathrm{N}=7)$ reported having used it to find job-related information, suggesting that the popularity of social media for job search that Pew identified in 2015 is continuing to grow [24]. Five $(\mathrm{N}=5)$ participants described using Facebook or Instagram to find out about jobs, extending "word-of-mouth" to the digital age. Less than half $(\mathrm{N}=5)$ of our job seekers mentioned they had gone to employment agencies or community centers.

\section{Finding Out About Jobs Online}

Participants had positive feelings about using the Internet to find out about jobs. The majority of our participants $(\mathrm{N}=8)$ discussed Indeed (www.indeed.com), a website that enables users to search a large database of jobs and apply directly though the site. Participants also mentioned Craigslist $(\mathrm{N}=2)$ and Google $(\mathrm{N}=7)$ as websites they would use to look for jobs. All but one of the participants $(\mathrm{N}=10)$ said that they used Google to answer job-related questions, and seven $(\mathrm{N}=7)$ reported that they had used Facebook for the same purpose. One participant described using Facebook and Instagram to passively find out about jobs, joining relevant Facebook groups or receiving job 'memes' that advertised hiring campaigns. 
Basically, I would say it's easier now to go online and find jobs because, it's through word of mouth. Like I say, with social media you don't have to be walking down the street to find [jobs]. Back then, it was to walk into these places and go "Hey, you guys hiring?" "No, we not hiring." You're going round for five, six, eight hours a day trying to fill applications and go to these places. [...] Now, with social media, it's everybody that's coming and telling you about these jobs. - Charlie

Four job seekers $(\mathrm{N}=4)$ even went beyond the standard procedure for learning about jobs, using various web services to advertise their skills as an employee or a contractor and waiting for interested parties to contact them. Marika used Indeed to upload her resumé, and frequently received calls from employers who found her through the site. Two participants owned small businesses, and used social media to promote them and find clients. Annie was a florist, and posted her work on Facebook and Instagram. Luke owned a landscaping business, and found clients through posting on Facebook, as well as through word of mouth.

\section{Learning about Jobs through Personal Contacts}

As established in earlier work [13, 25], word of mouth is very important for learning about jobs. Ten participants explicitly stated that they learn about jobs through 'word-of-mouth.' It was especially important for job seekers with low digital literacy; Aaron and Tanzer both had limited access to the Internet, so they relied on word of mouth and impromptu job offers to make ends meet. Tanzer was only able to access the Internet through a close friend, who would performed searches for Tanzer and later report back to him with the results. Two others were so confident in their social networks that they did not feel the need to turn to web search.

Everybody trying to keep me busy because like I said I've been homeless, I'm still kind of like homeless even though I stay with my cousin, but I'm still homeless because I'm staying with somebody. - Luke

Many participants $(\mathrm{N}=6)$ had a close relative, friend, or mentor who knew the details of their job interests, skills, and experience, and would forward relevant opportunities to the job seeker. At the time of his interview, Charlie was excitedly pursuing a program in law-enforcement that he had learned about through his pastor's son.

This was talked about at least six years ago. He brung [the job listing] back to me just this past Memorial Day, when I was over there for the holiday. He told me to come to his job, to his school and get the information they going to meet, and the guy told me to give him a call. - Charlie

Rather than relying on a large network of weak ties to learn about jobs, it seems that many of our participants $(\mathrm{N}=7)$ relied on a close relationship with an individual with very high social capital, who acted as an information broker. The information broker was generally someone older and more professionally successful than the corresponding participant, and the relationship between job seeker and broker was maintained through regular contact on a weekly or even daily basis.

\section{Accessing Important Job Details}

Although the Internet provides access to many job listings, many of our participants $(\mathrm{N}=6)$ had unanswered questions regarding jobs they were interested in. These questions were related to wages, benefits, job details, and workplace culture. Answers to these questions were important for helping our job seekers decide where invest their limited time and resources. Four participants said that there was no reliable way to get this vital information before they went to the official interview, or even until orientation.

"How much is this job paying?" [...] That was one of those questions that people ask you not to ask, because people be wanting you to come to these jobs and work for free, in my eyes. They'll tell you, "we'll discuss that with you once you get the job." - Charlie

Similarly, even after receiving an offer, Annie did not ask about the pay rate, benefits, or schedule, out of fear that the employers would change their minds about hiring her if she asked. Since they could not go directly to the employers for this information, job seekers turned to other sources.

While some information was available online, some participants reported that it was inaccurate or untrustworthy. Eight participants $(\mathrm{N}=8)$ explicitly stated that they preferred using social connections over Internet search for getting details about a job. In general, our participants trusted personal, social information more than information hosted by large online sites. One participant $(\mathrm{N}=1)$ even described using Facebook to research a potential workplace by reading existing employees' statuses. Institutions supported this stage of search indirectly by providing public computer labs, but no participants described a situation in which an institution directly helped a job seeker get more details about a potential job.

\section{Researching Job Details Online}

Participants conducted their own research of potential employers online, using sites like Google, Wikipedia, and Glassdoor, but they did not trust the information to be as accurate as what personal contacts would say. Talia was particularly concerned with scouting the workplace culture at a new job, going so far as to find existing employees on Facebook to see if they said anything about their job on their personal social media.

If I find a job that I want or I think I want, I'm going to Google. I'm gonna ask Siri if I have to. I'm going to social media. I'm gonna find someone that works for this company, and I'm taking it as far as looking this individual up, current or previous employee. I'm gonna look them up on social media and see what kind of stuff they post. Some people be like, "my job sucks, terrible day at work, hate my boss." I'm like... Maybe that's not good. - Talia

Talia wanted to know as much as possible about any potential employer, and leveraged all of her available resources to learn as much as she could. Still, she felt that information she received from social connections were more trustworthy. Marika also trusted information she got from individuals more than what she found through online reviews. 
I think you get it more accurate from a person that probably worked there before. [...] Just personal experience, I had a hospital job I was trying to apply for and I ended up running into one of the co-workers and they actually had a family member that worked there. We was cool enough. I was talking with them and they kind of gave me more of an accurate account of the company. Now when I was reading reviews ... If I went off the review, I wouldn't have been interested in the company. - Marika

Talia specifically distrusted online reviews, as she suspected that they might be tailored to make employers look good.

An answer that I get on Facebook is probably more honest than Glassdoor, because it's ... just think of Amazon, or think of a website when you're rating a product. If it's not good or it's a little too honest, they're not gonna post it; and they do the same thing with Glassdoor. Some things they will not post. - Talia

Talia and Marika both found discrepancies between what they found online and what they heard in person. Consistently, they trusted what they found through personal connections over information found on the web.

\section{Getting Job Details through Personal Contacts}

Job seekers with large social networks preferred to get information from personal contacts rather than online search. Four participants said they trusted information they received inperson more than information they found online, because they could read body language and assess the quality of information more accurately.

I'd like to know about the work place culture; and some questions that I have, I prefer to ask in person, because I want to see your facial expressions. I want to see the look on your face when I ask you the question. I want to see the body language. - Talia

I like to speak to a person. We in a new era now. Don't get me wrong. We in the media age, but I like to speak to a person face to face. [...] Not being prejudice, but I can't talk to a machine. - Brandon

Some participants asked their co-workers or family members about specific workplaces, or about employers that would be flexible to specific needs. In Winona's case, she needed an employer that would be flexible with her son's chronic medical emergencies. Her sister had previously worked at the Hilton, and advised her to apply there. Winona now works there, and found that her sister's tip was accurate.

She said they're very good with [medical emergencies] as long as you give them, you know, a heads up about everything, and give them proof. They haven't had any problem with that. - Winona

Marika also had a close connection who provided her with valuable job leads and all of the important information that she needed in order to evaluate the opportunity.

[My friend] always knew I was looking for a job or she always knew I was looking for a certain type of pay. We were kinda cool like that. She always was on it. She was like "they're hiring over here. You know they start off here." She always knew how much they starting off. She'd be like "they offer these benefits." - Marika

Not only did close contacts route high quality job leads to our participants, they frequently provided information about those jobs that informed job seekers' subsequent decisions.

\section{Applying to Jobs}

Beyond the efforts to acquire as much information as possible about a job, the next step in gaining employment is applying to a job. In the case of Indeed and similar sites, the jobfinding stage may transition directly into the applying stage. Participants described issues related to submitting applications online, and how they received help in knowing where and how to apply to a job, how to write their resumé, and how to present themselves in an interview. Three participants voiced the concern that the Internet made it harder to stand out as an individual. Additionally, job seekers described problems when using a smartphone to access these services and apply to jobs online, which presents a barrier for those without access to a desktop or laptop computer. Though many participants used online sites to apply for jobs, none of them had used online sites to improve a resumé. Instead, job seekers turned to social connections and institutions to provide expertise and advice regarding application materials.

\section{Applying to Jobs Online}

Since everybody can apply to a vast number of jobs online, you have much slimmer chances of catching an employer's attention without some external influence. Even though you can apply to many more jobs than you could before the Internet, you can still end up spending hours filling out applications.

I just believe that it's just a volume of people that's applying. [...] Even my daughter, she's 19. She's been looking for a job and she'll go to a McDonald's and say, "Hey, are you hiring?" They'll say, "Yes, go online. Go to this website and our store number is this." So it's still very unpersonable and it's still very hard to follow up with anyone because you're just a number and not a person, on the Internet. [...] And it's like you're waiting diligently just to get a response but you can have 30,000 people ahead of you. - Helen

While these Internet-based tools enable people to apply for more jobs, they have not necessarily lessened the importance of referrals that Smith [25] identified before rise of online applications. Two job seekers also voiced concerns about the technological requirements of online applications.

I believe having a desktop or a laptop also will help people more because you have a lot of places where you can go to search for jobs but I believe having that laptop, or computer, it makes it easier. Because on your phone, sometimes you can fill out applications and submit resumés but because of it being a phone and not an actual desktop and laptop it's harder for you to submit the application, or do an assessment, because a lot of times companies will have you fill out an application and then you'll have an assessment right after. So if you 
don't do the assessment it's like you never filled out the application. - Helen

Access to a desktop or laptop computer was considered to be essential for online applications, as some content did not work properly on smartphones.

\section{Social Advice on Applying to Jobs}

As we observed for earlier stages of the job search, those with large social networks still utilize their offline connections to learn when and how to apply to jobs.

I got co-workers that actually work at other places. So like, "Is your [company] hiring right now? Okay well I'm gonna try to apply." And they let me know what the website is or do I need to go in and fill out an application stuff like that. [...] A lot of stuff came through word of mouth. - Marika

In addition to gaining insider knowledge of specific employers, job seekers sought advice from mentors regarding resumébuilding and interview tips. For example, Winona was concerned about explaining gaps in her resumé and her son's medical needs during an interview, so she turned to her brother for advice, and he coached her on how to present it.

[My brother] been working since he was 18. [...] he hires, he interviews people, so at his job, so I know that he could give some good input about what I should say, what I shouldn't say, and, you know, how to make my resumé look more attractive to the employer. - Winona

When applying to jobs, job seekers who had concerns about the quality of their resumé or their interviewing skills would turn to these mentors for advice, not just because of their expertise, but also because of their close personal relationship with the job seeker.

\section{Securing a Job Offer}

The final stage of gaining employment is actually getting a job offer from an employer. Many of our participants who struggled to find work did not know why their applications went unanswered, particularly those who did not even get called for an interview. Participants who were employed emphasized the importance of their social connections to find referrals or insiders that provided support that improved their chances of getting a job. As was the case with applying to jobs, the Internet was of little use to our participants in bridging the gap between applying for jobs and actually obtaining them. Participants were concerned that online applications made it harder to stand out without these social advantages of referrals and insider information, though some conceived of using their social media accounts to find contacts at companies where they might want to work. The role of institutions was mixed. For some, community organizations offered valuable training programs or helped job seekers connect with appropriate employers; however, accessing these resources could be a long and frustrating process.

\section{Struggling to Stand Out Online}

Only one of our participants said that she found desirable jobs by using online employment tools. Participants who consistently struggled to find work through Internet resources did not know what they were doing wrong, as these systems provide little feedback or opportunity to stand out, less so than the traditional, offline process of applying.

I think coming in person, filling out an application, is 10 times better. I know we shouldn't, what's to call it, judge on an appearance, but I think that means a lot to me. [...] Appearance, you know. It shows you what you're getting yourself into, when you go and present yourself. You go and ask for an application, you fill the application out, the whole way. Then you say, "Here you go." You come nice[ly] dressed. That to me, all plays a role. - Charlie

Since online applications prevent individuals from standing out, Helen argued that they actually make it more important to have a referral or insider to influence the hiring process. Helen further proposed personal social media as a valuable tool to finding these insiders.

I plan to go on Facebook and search jobs that way. Because a lot of times you have friends, family members, extended friends that you haven't seen or talked to in a long time that may work for that particular company and you can inbox them on Facebook like, "Hey, is your company hiring? Can you put in a good word?" - Helen

Helen proposed using her Facebook in a way that resembles professional social media sites, such as LinkedIn. Only one of our participants used LinkedIn, but she trusted Facebook more, viewing it as a personal and thus more honest platform.

LinkedIn is for professionals, and Facebook is social media. I know LinkedIn is a form of social media, but I think [employees would] be more honest on Facebook versus LinkedIn. - Talia

\section{Finding Insiders in Your Social Network}

For many job seekers, a close relative or friend was crucial to finding available work, connecting with an insider referral, or navigating corporate bureaucracy.

I was just having trouble because it took so long for people to respond so I was always wondering why is it taking so long? Why are they not responding within the two week period or whatever when I applied for it. [...] I had actually just seen this person, they were smoking or whatever. [...] So I was like "What takes them so long to call people back? Because I applied here before and they never contacted me yet." [...] They said "well we hire within. We hire people who are referred by other employees." - Marika

If I can't find someone that I know, I'll try my mom. My mom's a barber, and she knows tons and tons of people. She knows someone everywhere we go. - Talia

Previous work has identified barbershops as information hubs within black communities, providing opportunities for distinct social groups to mingle and share information [11]. Having a 
barber as a close personal contact would be very valuable for establishing connections with relevant insiders.

Other participants were fortunate enough to have direct connections to insiders. While waiting for an offer from a manufacturing plant, Helen found that someone in HR was giving applicants that she knew preferential treatment. She was eventually able to successfully get the job, because her son worked at the company, and gave her the contact information for a different HR representative.

There was a lady there who was like pulling people in that she personally knew or that someone at the company personally knew and they wasn't sending them through the process that they should have been sending them through. [...] So I just kept being persistent. The first, second week of February I'm like, "Hey, what's goin' on. My son works there so I know people are comin' in. You guys are havin' new groups comin' in and you said my number's 21 . What's my number now?." "Oh, you're still 21." So at that point, they knew my name, they knew I kept calling in so at that point, the hiring manager basically was like, "The next orientation, pull her in." - Helen

Two other participants described similar situations, in which a close personal contact would not only help them find jobs, but guide them through additional steps, such as contacting a hiring manager directly, to improve their chances of getting the job. This behavior is consistent with past work that asserts the value of these close connections [13,25], and our interviews did not uncover any examples of job seekers detecting or resolving these barriers without these relationships.

\section{Institutional Support for Employability}

Community organizations helped job seekers actually get a job through skill-building, offering resumé-building workshops, mock interviews, and other training programs. In one case, the VA hospital consistently helped a job seeker find work when he needed it. On the other hand, two of the participants who sought help from employment agencies complained about how long the process took, and how obscure it was. Winona applied for funding from an employment agency for a nursing assistant certification. She eventually gave up, frustrated by the number of hoops she had to jump through and the lack of transparency throughout the process.

They took you through so much stuff in order for you to get [the training]. [...] they just like you have to go through this, this, even if you read all the information they say, they say you have to have a updated resumé. [...] you gotta bring your ID, social security card, your birth certificate, your proof of your income, um, how many people in the household, etc. [...] I did all that. Then you still have to wait. [...] They'll put you on a waiting list. And then they'll see if it's feasible to give you the money. It just too much, too much red tape. - Winona

The services that public institutions offer align with the important needs of low-resourced job seekers; however, issues such as excessive bureaucracy or limited outreach discourage some job seekers from utilizing on them.

\section{DISCUSSION}

Our interviews uncovered the important resources used by underserved job seekers, and how these resources are leveraged in four distinct stages of the job search process. While online resources are widely used to help job seekers find relevant job opportunities, they do not address issues that low-resourced job seekers encounter in accessing important job details, applying to jobs, and securing job offers. In this section, we discuss the benefits of both employment search platforms and social media for enhancing the job search, but we emphasize that these benefits are not evenly distributed. We note that those job seekers who were successful online were those who already had the skills and resources to succeed in the job search.

Employment search platforms provide access to many relevant job listings, and enable a new form of job seeking in uploading a resumé for employers to browse. As established in prior work, social connections are still a vital resource for job seekers $[12,13,25]$; however, social activities related to the job search, including learning about jobs through "wordof-mouth" and searching for referrals, are moving to social media platforms, in alignment with Pew Research Center's 2015 findings [24]. Rich social media feeds also extend the limits of networked information diffusion, exemplified by a participant who used strangers' social media posts about their workplaces to gain insight into potential job opportunities.

Despite these exciting developments, the benefits of online resources are concentrated among those job seekers who are already successful. Marika, the only participant who reported finding work through employment search platforms, was already employed and had a large social network that supported her. The participants who used social media for job-related activities had strong social networks offline as well, and recognized the importance of referrals for success in the job search, as established by past work [13, 25]. For those job seekers who lack sources of advice or feedback to help guide their job search process, online systems do little to help. We argue that this aligns with Toyama's Amplification Theory, which states that technology amplifies the capacity of users, but does not substitute for their deficiencies [27]. Job seekers who struggled to leverage their social networks could not easily find accurate or trustworthy information about the jobs they were interested in pursuing, which aligns with recent work in HCI in other low-resourced contexts $[4,18,30]$. They also struggled to access information about hidden requirements of job applications, such as the need for a referral or the contact information for the person in charge of hiring.

Systems that aim to support all job seekers must expand the services they provide. They must go beyond enhancing job seekers' existing activities and provide a platform that enables users to reflect on their own strengths and weaknesses, and learn how to leverage their resources to succeed in the job search process. In the next section, we apply our framework of the stages of job search to highlight major issues our participants face, and present design recommendations for online employment systems to address them. 


\section{DESIGNING TO SUPPORT THE JOB SEARCH PROCESS}

The existing set of online systems for employment does not support job seekers who struggle with finding trustworthy information, reflecting on the need to change, and recognizing the importance of social resources in their job search. Our results suggest that while online and social resources do a great job of supporting the first stage of the job search process (learning about relevant jobs), the remaining three stages are not well supported by online resources: Accessing Important Job Details, Applying to Jobs, and Securing a Job Offer. We provide a set of recommendations to design for low-resourced job seekers across these three stages.

\section{Accessing Important Job Details: Connect with Trustwor-} thy Sources of Information

When attempting to access important job details, job seekers identified distrust of job information as a key barrier, which is consistent with past research $[4,30]$. Aaron, Charlie, and Annie all said that they were uncomfortable asking employers about job details. Annie was afraid of being reprimanded for seeking information, while Charlie felt that employers would look down on him for asking about money. These participants perceived a major power imbalance between themselves and their potential employers. Dombrowski et al. found similar issues of information suppression by employers of low-wage workers across the US [9]. While the Internet provides access to some information about employers and job details, our participants treated the content with distrust; they suspected the information of being censored in favor of companies, being biased due to employees fears of posting negatively about an employer, or being intentionally deceptive as part of an employer's hiring strategy.

Drawing on Dombrowski et al.'s [10] framework for designing for social justice, we recommend designing for enablement, which they define as "facilitating and developing opportunities for people to fulfill their own potential and develop their own capacity." Our participants found anonymous and private content more trustworthy, and they believed it would encourage people to speak more honestly without fear of repercussions. Thus, we recommend allowing users to send anonymous, private questions to past employees at a targeted workplace. Our participants also expressed concerns about applying online to a job that was no longer available or that had already received thousands of applications. We recommend employment platforms highlight this information in job listings wherever possible, to help users decide if an application is worth their time and to improve the trustworthiness of the information.

\section{Applying to Jobs: Foster Engagement and Reflection}

While some participants appreciated the simplicity of applying to jobs on employment search platforms, many were frustrated by the lack of feedback they received. Some job seekers spent months applying to jobs without any response, never considering that they may need to change their practices in order to succeed. Two of our interviewees admitted that they had not considered that there may be issues with their resumé or other parts of their application that could be holding them back. Many low-resourced job seekers use these platforms on a daily basis, but the depth of engagement is limited. To address this gap, we adapt three strategies for fostering engagement from the design literature: expanding support for goal setting, prompting periodic reflection on goals, and providing improved social features [16].

First, we recommend employment platforms engage users about their long-term career goals, and help them plan accordingly by suggesting career paths, identifying gaps in their skills, and highlighting valuable training and credentials. A similar suggestion was made to support economically distressed job seekers [19] and learners taking Massive Open Online Courses (MOOCs) [8]. Second, we recommend systems engage with users about submitted applications and interviews, asking preset questions about how they presented themselves or what they thought went well or poorly in an interview, to prompt users to reflect more deeply on their application process. Third, we recommend that designers of employment platforms consider ways for users to view application materials and performance metrics of themselves and peers. For example, a system may provide a user with anonymized resumés from other users who applied to similar jobs in the past and received callbacks or offers, and highlight differences between the two applications, extending past work on how to provide resume feedback to disadvantaged job seekers [5]. Alternatively, prominently displaying basic metrics of applications submitted, interviews, and job offers could help struggling job seekers recognize when their experiences are different from a larger population of users. These features provide a combination of system-driven feedback on application materials and opportunities for users to identify areas in which they could improve, either on their own or with feedback from personal connections.

\section{Securing a Job: Support Social Connections}

Our findings reinforce past research that indicates that social connections and referrals are vital for securing a job [12, 13, 25]. Many of our participants were fortunate enough to have personal connections who could provide guidance and feedback in the job search process, or who could act as an insider or referral to bolster the job seeker's chances of securing a job. However, some job seekers may not be aware of the importance of these social resources in the job search, or may not know who to contact for advice [4].

Extending our recommendation that platforms engage with their users more deeply, we suggest educating users about the value of social resources for their job search, to reduce the information inequality between job seekers. More elaborate designs could enable users to link their social media accounts to leverage their existing networks in their job search. Combined with the goal-related suggestions above, systems could highlight social network contacts who have the skills or careers that make users' aspirations, helping them to identify potential mentors. Social network data could also be used to identify contacts who work at companies that have relevant job openings, and search results could be filtered or ranked based on the prevalence of these connections. These features would emulate traditional social networking and mentorship, and help job seekers identify opportunities to leverage their social connections to improve their chances of gaining employment. 


\section{LIMITATIONS AND FUTURE WORK}

This is an exploratory study that investigates the resources that low-resourced job seekers employ in their job search process. We identify two key limitations of our work. First, we conducted this research in a single metropolitan area in the Midwestern US. Experiences of low-resourced job seekers in other parts of the US and the world may vary significantly. Future work should examine differences in perceptions across regions; such an analysis could infer causal relationships between local policy factors and the outcomes for job seekers.

Second, our results represent the job seeker perspective, yet there are questions raised that can only be addressed from the perspectives of employers' and platforms' perspectives. Accordingly, our design recommendations reflect the job seekers' interests, and do not thoroughly account for the interests of platforms and of employers (who are the primary source of revenue for most job search platforms [26]). Many of our recommendations aim to expose information that, from our participants' perspectives, employers would rather keep private, as it could lead to fewer applicants or even negative publicity. We also recommend a significant philosophical shift in these sites, from a tool-based search platform to something more akin to modern wellness and fitness applications. Such a shift may drive away users who are simply looking for a search engine, and do not need or want this additional support. Future work should explore the perspectives of employers and platform designers in order to identify discrepancies between various perspectives, and to refine these recommendations to suit the needs of all stakeholders.

\section{CONCLUSION}

In this work, we examine the roles of important information resources in the job search process of low-resourced job seekers through semi-structured interviews. We find that, while personal social connections remain vital for the majority of job seekers, online employment search platforms and personal social media sites enhance job seekers' existing practices and afford innovative forms of job seeking. However, these online resources do not help job seekers identify problems in their job search or overcome structural barriers. To empower job seekers experiencing these issues, we call for employment platforms to engage with their users by conceiving of the job search as an extended, goal-oriented process. To achieve this, we propose designs recommendations that support access to trustworthy information about jobs and employers, prompt reflection about activities throughout the job search, and identify valuable opportunities to leverage social relationships in both the job search and in long-term career development.

\section{ACKNOWLEDGMENTS}

We would like to thank Drs. Kentaro Toyama, Soo Young Rieh, and Julie Hui, and Ed Happ for insightful conversations and suggestions regarding our findings and discussion. Finally, we thank our CHI reviewers for excellent criticism and feedback that helped us refine the contribution and presentation of this work. This work was supported by the National Science Foundation, under grant (IIS-1717186), and the University of Michigan's Rackham Graduate School.

\section{REFERENCES}

1. 2016. 2012-2016 American Community Survey 5-Year Estimates. Technical Report. U.S. Census Bureau. https://factfinder.census.gov/faces/nav/jsf/pages/ community_facts.xhtml

2. Elfreda A Chatman. 1991. Life in a Small World: Applicability of Gratification Theory to Information-Seeking Behavior. Journal of the American Society for Information Science 42, 6 (1991), 438-449.

3. Elfreda A Chatman. 1996. The Impoverished Life-World of Outsiders. Journal of the American Society for Information Science and Technology 47, 3 (1996), 193-206.

4. Tawanna R Dillahunt. 2014. Fostering social capital in economically distressed communities. In Proceedings of the 32nd annual ACM conference on Human factors in computing systems (CHI '14). ACM, New York, New York, USA, 531-540. DOI : http://dx.doi.org/10.1145/2556288.2557123

5. Tawanna R Dillahunt, Nishan Bose, Suleman Diwan, and Asha Chen-Phang. 2016. Designing for Disadvantaged Job Seekers: Insights from Early Investigations. In Proceedings of the 2016 ACM Conference on Designing Interactive Systems. ACM, 905-910.

6. Tawanna R Dillahunt, Vaishnav Kameswaran, and Tanya Rosenblat. 2017. Uncovering the Values and Constraints of Real-time Ridesharing for Low-resource Populations. In Proceedings of the 2017 CHI Conference on Human Factors in Computing Systems (CHI'17). ACM.

7. Tawanna R Dillahunt and Amelia R Malone. 2015. The promise of the sharing economy among disadvantaged communities. In Proceedings of the 33rd Annual ACM Conference on Human Factors in Computing Systems. ACM, 2285-2294.

8. Tawanna R. Dillahunt, Sandy Ng, Michelle Fiesta, and Zengguang Wang. 2016. Do Massive Open Online Course Platforms Support Employability?. In Proceedings of the 19th ACM Conference on Computer-Supported Cooperative Work \& Social Computing (CSCW'16). ACM, New York, NY, USA, 233-244. DOI :

http://dx.doi.org/10.1145/2818048.2819924

9. Lynn Dombrowski, Adriana Alvarado Garcia, and Jessica Despard. 2017. Low-Wage Precarious Workers' Sociotechnical Practices Working Towards Addressing Wage Theft. In Proceedings of the 2017 CHI Conference on Human Factors in Computing Systems. ACM, 4585-4598.

10. Lynn Dombrowski, Ellie Harmon, and Sarah Fox. 2016. Social Justice-Oriented Interaction Design. In Proceedings of the 2016 ACM Conference on Designing Interactive Systems - DIS '16. ACM Press, New York, New York, USA, 656-671. DOI :

http://dx.doi.org/10.1145/2901790.2901861 
11. Karen E Fisher and Charles M Naumer. 2006. Information grounds: Theoretical basis and empirical findings on information flow in social settings. New directions in human information behavior (2006), 93-111.

12. Mark Granovetter. 1973. The Strength of Weak Ties. The American Journal of Sociology 78, 6 (1973), 1360-1380. DOI : http://dx.doi .org/10.1037/a0018761

13. Mark Granovetter. 1974. Getting a job: a study of contacts and careers. The University of Chicago Press, Chicago, USA.

14. Mark Granovetter. 1983. The strength of weak ties: A network theory revisited. Sociological theory (1983), 201-233.

15. Anne E Green, Maria De Hoyos, Yuxin Li, and David Owen. 2011. Job Search Study: Literature review and analysis of the Labour Force Survey. Technical Report. Department for Work and Pensions, London, England.

16. Rebecca Gulotta, Jodi Forlizzi, Rayoung Yang, and Mark Wah Newman. 2016. Fostering Engagement with Personal Informatics Systems. In Proceedings of the 2016 ACM Conference on Designing Interactive Systems - DIS '16. ACM Press, New York, New York, USA, 286-300. DOI : http://dx.doi.org/10.1145/2901790.2901803

17. John F Helliwell and Robert D Putnam. 2007. Education and social capital. Eastern Economic Journal 33, 1 (2007), 1-19.

18. David G. Hendry, Norah Abokhodair, Rose Paquet Kinsley, and Jill Palzkill Woelfer. 2017. Homeless Young People, Jobs, and a Future Vision. In Proceedings of the 8th International Conference on Communities and Technologies - C\&T'17. ACM Press, New York, New York, USA, 22-31. DOI : http://dx.doi.org/10.1145/3083671.3083680

19. Benjamin Jen, Jashanjit Kaur, Jonathan De Heus, and Tawanna R. Dillahunt. 2014. Analyzing Employment Technologies for Economically Distressed Individuals. In CHI' 14 Extended Abstracts on Human Factors in Computing Systems (CHI EA '14). ACM, New York, NY, USA, 1945-1950. DOI :

http://dx.doi.org/10.1145/2559206.2581290

20. Ichiro Kawachi, Bruce P Kennedy, Kimberly Lochner, and Deborah Prothrow-Stith. 1997. Social capital, income inequality, and mortality. American journal of public health 87, 9 (1997), 1491-1498.
21. Michael Muller. 2014. Curiosity, creativity, and surprise as analytic tools: Grounded theory method. In Ways of Knowing in HCI, Judith S. Olson and Wendy A. Kellogg (Eds.). Springer, 25-48. DOI : http://dx.doi.org/10.1007/978-1-4939-0378-8_2

22. Cassidy Puckett and Eszter Hargittai. 2012. From Dot-Edu to Dot-Com: Predictors of college students' job and career information seeking online. Sociological Focus 45, 1 (2012), 85-102.

23. Robert D Putnam. 1995. Bowling alone: America's declining social capital. Journal of democracy 6,1 (1995), 65-78.

24. Aaron Smith. 2015. Searching for work in the digital era. Pew Research Center (2015).

25. Sandra Susan Smith. 2007. Lone pursuit: Distrust and defensive individualism among the black poor. Russell Sage Foundation.

26. Rodion Telpizov. 2017. How to Successfully Monetize Your Job Board Website. (2017). https://www. smartjobboard. com/blog/ monetize-your-job-board-website/

27. Kentaro Toyama. 2015. Geek Heresy: Rescuing Social Change from the Cult of Technology. PublicAffairs, New York.

28. Alexander Van Deursen, Cédric Courtois, and Jan Van Dijk. 2014. Internet skills, sources of support, and benefiting from Internet use. International Journal of Human-Computer Interaction 30, 4 (2014), 278-290.

29. Alexander Van Deursen and Jan Van Dijk. 2009. Using the Internet: Skill related problems in users' online behavior. Interacting with Computers 21, 5-6 (2009), 393-402. DOI :

http://dx.doi.org/10.1016/j.intcom.2009.06.005

30. Jill Palzkill Woelfer and David G Hendry. 2010. Homeless young people's experiences with information systems. In Proceedings of the 28th international conference on Human factors in computing systems - CHI '10. ACM Press, New York, New York, USA, 1291. DOI : http://dx.doi.org/10.1145/1753326.1753520

31. Jill Palzkill Woelfer and David G Hendry. 2012. Homeless young people on social network sites. In Proceedings of the SIGCHI Conference on Human Factors in Computing Systems. ACM, 2825-2834. 